\begin{tabular}{||ll||}
\hline Citation & $\begin{array}{l}\text { Muhammad Roil Bilad, Gergo Mezohegyi, Priscilla Declerck, Ivo Vankelecom, } \\
(2012), \\
\\
\text { Novel magnetically induced membrane vibration (MMV) for fouling } \\
\text { control in membrane bioreactors, } \\
\text { Water Research, 46(1), 63-72. }\end{array}$ \\
\hline Archived version & $\begin{array}{l}\text { Author manuscript: the content is identical to the content of the published } \\
\text { paper, but without the final typesetting by the publisher }\end{array}$ \\
\hline Published version & $\underline{\text { http://dx.doi.org/10.1016/i.watres.2011.10.026 }}$ \\
\hline Journal homepage & $\underline{\text { http://www.iwaponline.com/wr/default.htm }}$ \\
\hline Author contact & $\begin{array}{l}\text { muhammadroil.bilad@biw.kuleuven.be } \\
+32(0) 16376681\end{array}$ \\
\hline IR & $\underline{\text { https://lirias.kuleuven.be/handle/123456789/345896 }}$ \\
\hline
\end{tabular}

(article begins on next page) 



\title{
Novel magnetically induced membrane vibration (MMV) for fouling control in membrane bioreactors
}

\author{
Muhammad R. Bilad ${ }^{a}$, Gergo Mezohegyi ${ }^{a}$, Priscilla Declerck ${ }^{b}$ and Ivo F.J. Vankelecom ${ }^{a}$
}

${ }^{a}$ Centre for Surface Chemistry and Catalysis, Faculty of Bioscience Engineering, Katholieke Universiteit Leuven, Kasteelpark Arenberg 23, Box 2461, 3001 Leuven, Belgium

baboratory of Aquatic Ecology and Evolutionary Biology, Katholieke Universiteit Leuven,

Ch. Deberiotstraat 32, 3000 Leuven, Belgium 


\begin{abstract}
Conventional submerged membrane bioreactors (MBRs) rely on the coarse bubbles aeration to generate shear at the liquid-membrane interface to limit membrane fouling. Unfortunately, it is a very energy consuming method, still often resulting in a rapid decrease of membrane permeability and consequently in higher expenses. In this paper, the feasibility of a novel magnetically induced membrane vibration (MMV) system was studied in a lab-scale MBR treating synthetic wastewater. The effects on membrane fouling of applied electrical power of different operation strategies, of membrane flux and of the presence of multiple membranes on one vibrating engine on membrane fouling were investigated. The filtration performance was evaluated by determining the filtration resistance profiles and critical flux. The results showed clear advantages of the vibrating system over conventional MBR processes by ensuring higher fluxes at lower fouling rates. Intermittent vibration was found a promising strategy for both efficient fouling control and significant energy saving. The optimised MMV system is presumed to lead to significant energy and cost reduction in up-scaled MBR operations.
\end{abstract}

\title{
Keywords
}

magnetically induced vibration, membrane bioreactor, membrane fouling, shear rate. 


\section{Introduction}

Membrane bioreactors (MBRs) have been widely investigated as an advanced wastewater treatment. Their advantages over the conventional activated sludge systems have been are widely cited throughout literature. However, their widespread application is still restricted, mainly due to the membrane fouling and its consequent capital and operational costs. Most traditional approaches for fouling control are based on optimizing operational conditions in favor of fouling mitigation, improving membrane properties and exploiting the hydrodynamics near the membrane surface (Le-Clech et al., 2006; Meng et al., 2009; Drews, 2010).

Hydrodynamic control is implemented via the cross-flow velocity in cross-flow MBRs, and as the secondary flow of the coarse air bubbles in submerged MBRs. Another technique is by moving the membrane itself relative to the feed, or by moving a mass near by the membrane surface. This technique is commonly known as dynamic or shear-enhanced filtration (Beier, 2008; Jaffrin et al., 2008).

In the submerged MBRs, the coarse bubbles aeration generates direct shear on the membrane surface by inducing a secondary flow of liquid that disrupts the mass transfer boundary layer, and promotes local mixing near the membrane surface (Cui et al., 2003). Despite the rather high energy input, this approach produces relatively weak shear rates. In addition, a "plateau" in terms of flux improvement is reached at a certain air supply (Genkin et al., 2006). Moreover, it is difficult to ensure a homogeneous bubble distribution (Genkin et al., 2006; Wu et al., 2008) and aeration at higher velocities can change sludge properties and hence diminish the biomass floc stability (Rosenberger and Kraume, 2002; Drews et al., 2005).

Considering the limited efficiency of the coarse bubbles aeration in submerged MBRs, the enhancement of shear rate via mechanical means, seems a potential option for fouling control. A couple of studies have investigated the performance of shear-enhanced filtration systems, such as the Vibratory Shear Enhanced Processing (VSEP) and Vibrating Hollow Fiber Modules (VHFM) (Genkin et al., 2006; Beier et al., 2006; Altaee et al., 2010; Beier et al., 2007; Beier et al., 2009). In the VHFM systems, the membrane is vibrated by a separated vibrating engine that produces axial oscillations. Membrane and engine are connected via a sliding rod.

Although all the referred studies reported a significant improvement on both the critical flux (CF) and the sustainability of operation, they face numerous limitations: (1) the vibrating system is often restricted to a small range of vibration amplitudes and frequencies; (2) because of the membrane unit is separated from the vibration engine, the obtained yield of shear rates is somehow reduced, due to energy loss resulting from the mechanical contacts and their friction; (3) in most cases, filtration is run in continuous vibration mode, without the ability of changing the vibration parameters during the filtration operation, hence not able to adapt to the needs of the mixed liquor that might change over time.

In the present study, a novel magnetically induced membrane vibration (MMV) system is proposed as an alternative shear enhancement device for fouling control in MBRs. As the vibrating engine is integrated in the membrane module, an as movement is magnetically induced, it is expected to experience less friction, to consume less energy and to have a very flexible vibration control. One of the main advantages of MMVs compared to the other shear-enhanced filtration systems, is their high flexibility for varying the operation modes in real-time, such as changing vibration amplitudes without interrupting the filtration to allow an online optimisation of the filtration performance. The unsteady fouling behavior coming from the dynamic changes in feed properties, can thus be controlled by real-time manipulation of the vibration parameters.

To our best knowledge, no such system has been reported so far. In this study, the efficiency of the MMV system to control membrane fouling was investigated in a lab-scale MBR treating synthetic molasses 
wastewater. The impact of several operation parameters on fouling were studied, including vibration-related factors (e.g., vibrating power, mode and cycle), membrane flux and presence of multiple membranes arrangement. In addition, the cost efficiency of the lab-scale MMV system was furthermore estimated and discussed.

\section{$2 \quad$ Materials and methods}

\subsection{Activated sludge and wastewater}

The activated sludge used to inoculate the lab-scale high-throughput-MBR (HTML, Belgium [Bilad et al., $2011^{\mathrm{a}}$ ]) was obtained from a pilot-scale MBR in the Waterleau wastewater laboratory (Wespelaar, Belgium) treating the same molasses wastewater, as the HT-MBR. The feed solutions were prepared by diluting 0.45 $\mathrm{ml} / \mathrm{l}$ of molasses stock solution. The characteristics of the feed were given in Bilad et al. $\left(2011^{\mathrm{b}}\right)$. The diluted molasses solution was chosen as feed wastewater, because it does not require pre-fine screening, it has a good COD/N ratio and contains trace elements (Yan et al., 2010). The bioreactor was operated at room temperature $\left(22^{\circ} \mathrm{C}\right)$ in a fed-batch mode during the parametric studies and continuous mode during the long-term filtration test.

\subsection{Membrane preparation and cleaning}

Two different flat sheet membranes were used during the experiments, a commercial chlorinated polyethylene membrane (KUBOTA, Japan) $\left(P E_{K}\right)$ and a commercial polyvinylidene fluoride membrane (Toray) $\left(P V D F_{T}\right)$. Both membranes were used to evaluate the effect of vibration on membrane fouling (Sections 3.2.1 - 3.2.2). Due to the limited amount of membrane material, $\mathrm{PVDF}_{\mathrm{T}}$ was used to investigate the vibration related parameters (Sections 3.2.3 and 3.3) and $P E_{K}$ was used for the experiments with multiple membranes (Section 3.4). These membranes were potted as described by Bilad et al. $\left(2011^{\mathrm{a}}\right.$ ). The active membrane surface area in each membrane was $0.016 \mathrm{~m}^{2}$. The SEM images of the membranes and their properties are summarized in Fig. 1 and Table 1 respectively. 


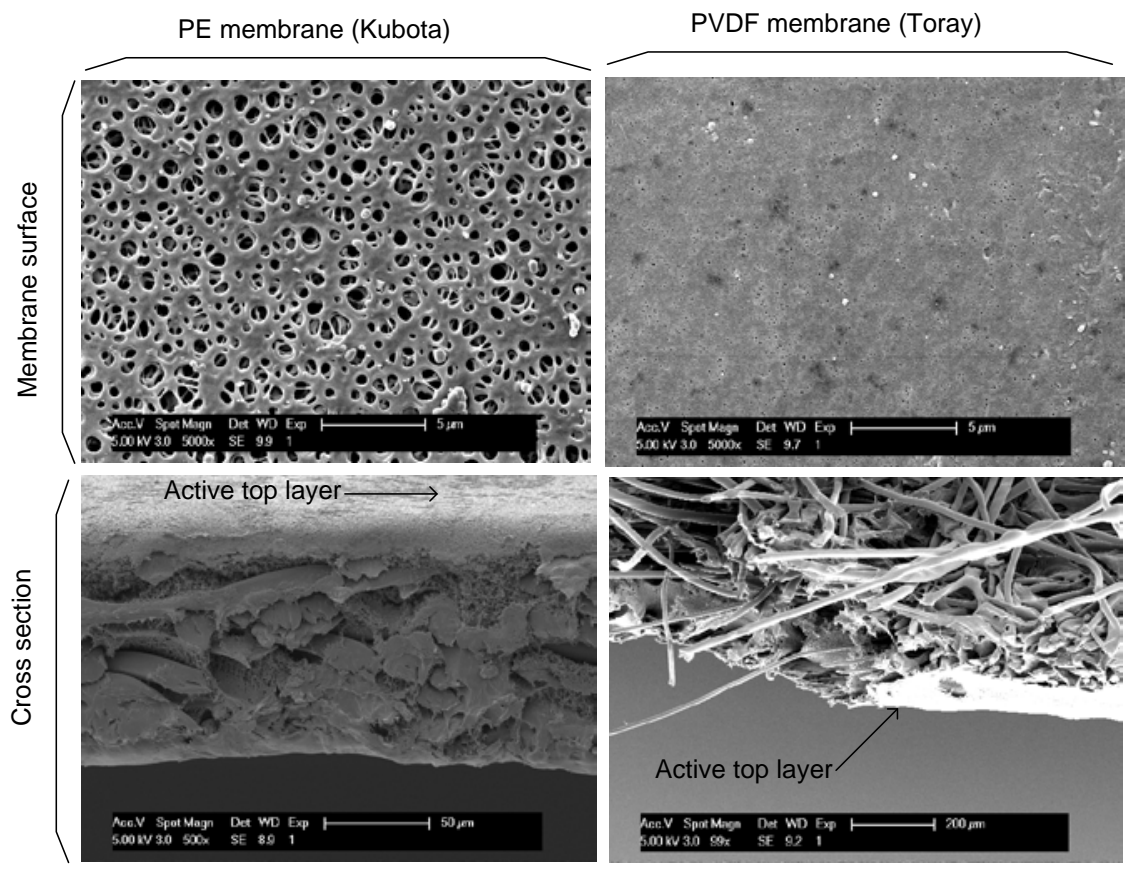

Fig. 1. SEM images of surface and cross section of the membranes used in this study.

Table 1. Main characteristics of the membranes used in this study.

\begin{tabular}{lll}
\hline Parameter & $\mathrm{PE}_{\mathrm{K}}$ & $\mathrm{PVDF}_{\mathrm{T}}$ \\
\hline Pore size (using imageJ) $(\mu \mathrm{m})$ & 0.4 & 0.08 \\
Pore size (supplier data) $(\mu \mathrm{m})$ & 0.22 & 0.03 \\
Surface porosity $(\%)$ & 11 & 0.2 \\
Thickness $(\mu \mathrm{m})$ & 165 & 320 \\
Morphology & Symmetric & Asymmetric \\
\hline
\end{tabular}

After each experiment, the module was removed from the bioreactor tank. First, physical cleaning was applied by flushing the membrane surface with pressurised tap water for $10 \mathrm{~min}$. Afterwards, permeability of the membrane was measured. Unless the permeability loss was less than $5 \%$, the membrane was chemically cleaned with $0.5 \mathrm{~g} / \mathrm{L} \mathrm{NaOCl}$ solution for $3 \mathrm{~h}$, resulting in quasi complete membrane permeability recovery in all cases.

\subsection{Experimental set-up}

A schematic diagram of the lab-scale MBR is shown in Fig. 2. The construction of the reactor system was similar to that of the HT-MBR developed earlier (Bilad et al., 2011 ${ }^{\mathrm{a}}$ ), except for the addition of the MMV system. The reactor had a working volume of $18.6 \mathrm{~L}$ and was virtually divided into aerated and non-aerated zones. In the former zone, two different aeration systems giving a total flow rate of $0.6 \mathrm{~m}^{3} / \mathrm{h}$ were provided: the fine bubbles aeration to provide soluble oxygen for the biological process, while the coarse bubbles aeration had a role in scouring the membrane surfaces as fouling control in a conventional submerged MBR system. In the non-aerated zone, a constant but weak movement of fluid was still present, induced by the air bubbles movement in the aerated zone. 
(a)

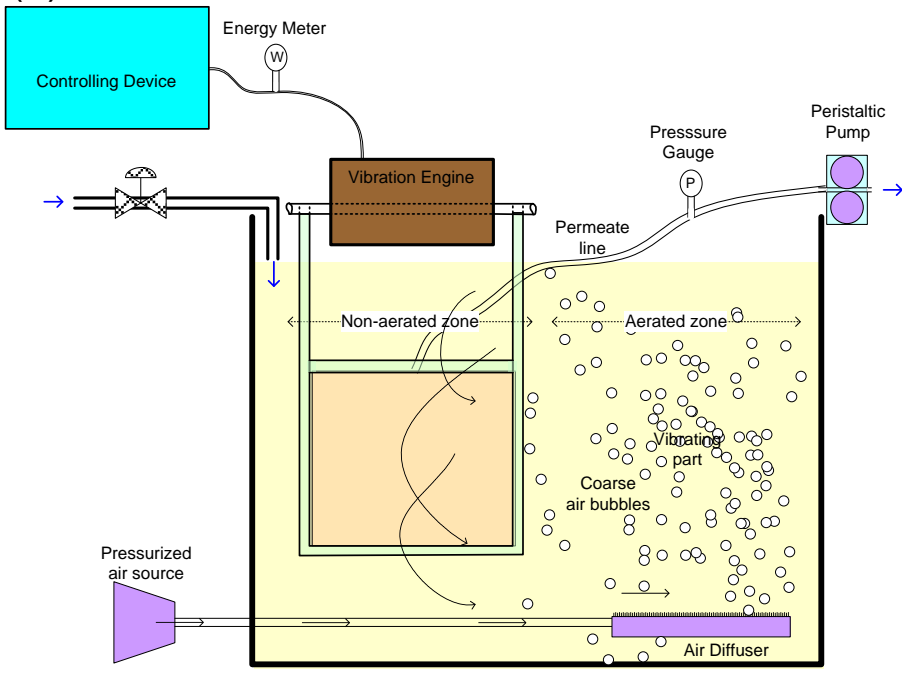

(b)

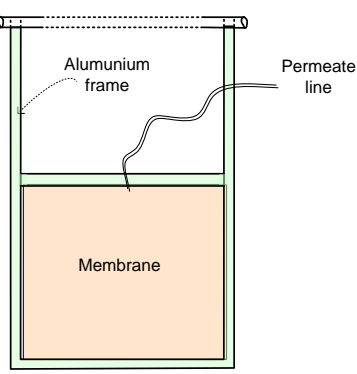

(c)

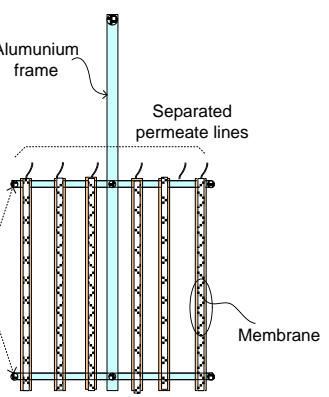

Fig. 2. Schematic diagram of (a) the HT-MBR set-up equipped with the MMV system, (b) the MMV module in front view, and (c) the MMV module in side view, showing the parallel position on the multiple membranes mounted.

In the MMV system, a magnetically induced vibration of the membrane is applied in order to provide shear at the liquid-membrane interface. The module is consists of one or more membranes that is integrated in the MMV module. The system includes a vibration driver, an electric wire, a vibration engine and the actual vibrating module. The signal is provided by the vibration driver being installed with a Test Tone Generator software (Esser audio, Germany). The vibration itself is created in the vibration engine by magnetic attraction/repulsion forces in a "push and pull" mode. The movement orientation of the vibrating part faces the narrow face of the module in order to both prevent the bumping of liquid onto the membrane and minimise the associated energy loss. The vibration moves the membrane to the left and the right through a sinusoidal pattern. The adjustable vibration parameters are the applied power (determined by combination of vibration amplitude and frequency), the vibration mode and the vibration cycle. The vibration amplitude and frequency can be supplied either with constant or variable values, while vibration can be run either in continuous or intermittent mode. During the filtration experiments, the vibration amplitude was limited to 2 $\mathrm{mm}$ at the most and the frequencies were adjusted between 0 and $60 \mathrm{~Hz}$. The real vibration power $\left(P_{V}, \mathrm{~W}\right)$ was later calculated in a first approximation from the electric current and electrostatic potential measured on the electrical wire by two AVO meters (DVM 890-Velleman, Belgium). Heat losses at the engine were thus included in the measurements.

\subsection{Determination of sludge characteristics and filtration parameters}

The mixed liquor suspended solid (MLSS), sludge volume index (SVI) and the feed and effluent quality were measured according to standard methods (APHA, 1992). The filtration performance was evaluated by determining the critical flux (CF) and filtration resistance values. The flux $\left(\mathrm{J}, \mathrm{L} / \mathrm{m}^{2} \mathrm{~h}\right)$ and membrane permeability (L, L/m ${ }^{2} h$ bar) were calculated by using eq.(1) and eq.(2), respectively: 


$$
\begin{aligned}
& J=\frac{\Delta V}{A \Delta t} \\
& L=\frac{J}{T M P}
\end{aligned}
$$

where $V$ is the permeate volume (L), $t$ the filtration time $(\mathrm{h}), A$ the membrane surface area $\left(\mathrm{m}^{2}\right)$ and TMP the trans-membrane pressure (bar, or $\mathrm{Pa}$ for filtration resistance calculation). The filtration resistance $\left(R_{T}\right.$, $\mathrm{m}^{-1}$ ) was calculated based on Darcy's law (eq.(3)):

$$
\begin{aligned}
R_{T} & =\frac{\mathrm{TMP}}{\eta J_{V}} \\
R_{T} & =R_{M}+R_{F}
\end{aligned}
$$

where $\eta$ is the dynamic viscosity of permeate $(\mathrm{Pa} \mathrm{s}), J_{V}$ the flow velocity $(\mathrm{m} / \mathrm{s})$ calculated from the flux, $R_{M}$ the intrinsic membrane resistance $\left(\mathrm{m}^{-1}\right)$, and $R_{F}$ the fouling resistance $\left(\mathrm{m}^{-1}\right)$.

Two typical types of filtration were performed throughout the study. The first filtration type was the conventional aerated filtration. In this case, the membrane module was placed into the aerated zone and the filtration was performed as in conventional submerged MBRs. The second filtration type was the vibrated filtration in which the membrane module was placed into the non-aerated zone, and the filtration was performed as a MMV system.

The CF $\left(\mathrm{L} / \mathrm{m}^{2} \mathrm{~h}\right)$ was measured using the stepwise method (Le-Clech et al., 2003). The applied initial flux, step height and step duration were $2 \mathrm{~L} / \mathrm{m}^{2} \mathrm{~h}, 2 \mathrm{~L} / \mathrm{m}^{2} \mathrm{~h}$ and $15 \mathrm{~min}$, respectively. This method was chosen because of its technical simplicity. To obtain the CF value, the final TMP values after each step were plotted against the fluxes. Below the CF, a linear relationship exists and the CF was determined as the flux at which this linear correlation ceased to exist. 


\section{$3 \quad$ Results and discussion}

\subsection{Bioreactor performance}

The acclimatization and biological performance of the sludge in the HT-MBR was discussed earlier (Bilad et al., $2011^{\mathrm{c}}$ ). To prevent the accumulation of slowly biodegradable substances during the fed-batch operation, a part of the liquid in the reactor was discharged every week. The activated sludge was settled and a part of the supernatant was withdrawn and replaced with tap water. During the test, the MLSS concentrations were kept at 10-12 g/l by partially withdrawing the sludge, while the SVI was in the range of 55-75 ml/g. During the continuous operation, the hydraulic retention time was set at $24 \mathrm{~h}$, to remove more than $98 \%$ of the chemical oxygen demand. No suspended solids were detected in the permeates for neither the aerated nor the vibrated modules. Comprehensive analysis of the biological performance was not carried out during this study, since the main objective - at the current stage - was to prove the effectiveness of MMV to control fouling.

\subsection{Effect of vibration parameters on membrane fouling}

\subsubsection{Membrane fouling at different filtration modes}

In order to observe the impact of the vibration on the filtration performance using MMV system, the filtration of the activated sludge was performed in four different modes:

- Mode-1: filtration in the non-aerated zone without vibration. In this mode, the fouling is only controlled by the limited movement of liquid induced by the aerated zone.

- Mode-2: subsequent filtration just after Mode-1 without cleaning the membrane. This mode was performed to observe the impact of vibration on cleaning a fouled membrane.

- Mode-3: filtration in the aerated zone ('aerated filtration'). The coarse bubbles aeration velocity was set at $0.3 \mathrm{~m}^{3} / \mathrm{h}$.

- $\quad$ Mode-4: filtration in the non-aerated zone ('vibrated filtration').

For Modes-2 and 4, the membrane was continuously vibrated at a frequency of $50 \mathrm{~Hz}$, corresponding to a $P_{V}$ of $12.5 \mathrm{~W}$. The purpose of selecting a relatively high $P_{V}$ in this test was to observe the maximum impact of vibration. For all modes, filtrations were run at a fixed flux of $22 \mathrm{~L} / \mathrm{m}^{2} \mathrm{~h}$ for $30 \mathrm{~min}$ and the filtration performance was evaluated using the resistance profiles. The virtual division of the MBR zones is schematically shown in Fig. 2.

Fig. 3 shows the resistance profiles of the four different filtration modes. Mode- 1 shows the highest filtration resistance followed by Mode- 3 , and -4 , for both tested membranes. This order clearly represents the shear rates at the membrane surfaces. In the non-aerated zone, the membrane surfaces experienced very limited shear rates, only from some movement of the bulk liquid. In the aerated zone, a higher degree of shear rates was realized at the membrane surfaces due to both the liquid movement and the air bubbles scouring. In the case of the vibrated filtrations, the shear rates were high enough to develop the back transport from the membrane that finally exceeded the fouling rate, thus promoting the removal of colloids, macromolecules and other foulants from the membrane surface. As a consequence, almost no fouling was built-up in Mode-4 by both the PVDF $\mathrm{T}_{\mathrm{T}}$ and $\mathrm{PE}_{\mathrm{K}}$ membranes. 
The impact of vibration to clean a fouled membrane is clearly seen from the results of filtration in Mode-2. A significant drop of filtration resistance was immediately obtained just after the vibration started. This result confirms the ability of the developed MMV system for in-situ cleaning of pre-fouled membranes. The impact of vibration might be different on membranes with different properties, as also shown when comparing Fig. $3 a$ with $3 b$. This will be the subject of future research.

The results confirmed the effectiveness of the MMV system in controlling membrane fouling. The vibration may control fouling via two mechanisms: (1) preventing the convective flow of foulants onto and into the membrane, as seen from the result in Mode-4 and (2) removing the foulants from the pre-fouled membrane, as seen from the result in Mode-2. It has to be noticed that this experiment was performed in a very short time span. Apart from the attachment of (bio)foulants, physico-chemical interactions with the membrane might also take place ( Le-Clech et al., 2006). This type of fouling is generally developed at a slower rate that could not be observed in the experiment above, due to both short duration and the detection limits of the applied pressure (TMP) gauges.
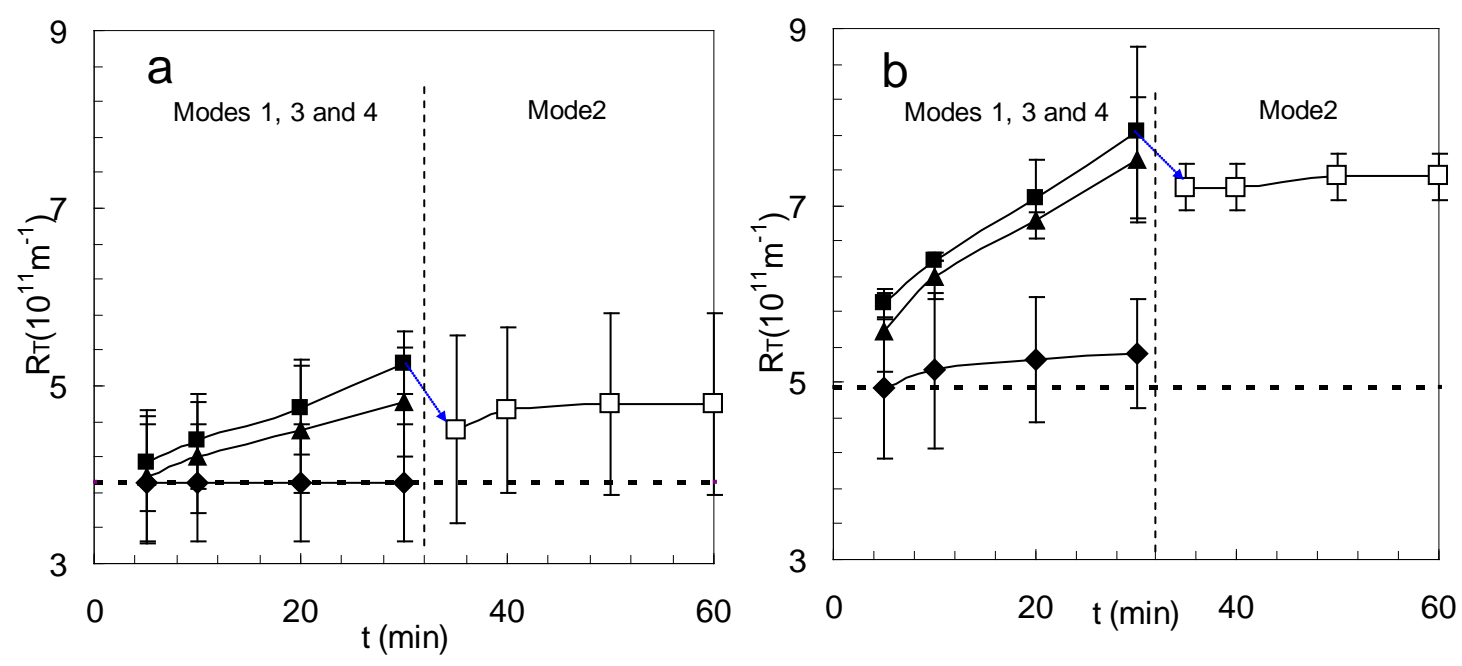

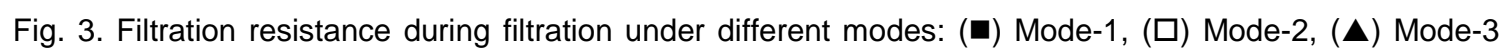
and $(\diamond)$ Mode-4, using (a) PVDF and (b) PE $E_{K}$ membranes.

\subsubsection{Effect of vibration power}

In the MMV system, the membrane movement is closely related to the amount of energy transferred to the system, which is on its turn transferred into shear. It is expected that at higher $P_{V}$, the membrane-liquid interface experiences increased shear stress. A few studies with vibrated membranes suggested that this shear rate strongly depends on the vibrating parameters and is determined as a function of both the vibration amplitude and frequency (Genkin et al., 2006; Beier et al, 2006; Beier et al., 2007).

A series of filtration tests was performed at different $P_{v}$, measured as the electric consumption by the vibration engine, in order to investigate its effect on membrane fouling. $P_{V}$ was varied by adjusting the frequency or amplitude of vibration and was set in the range of 0-13.8 W. The filtrations were performed for $30 \mathrm{~min}$ at a fixed flux of $22 \mathrm{~L} / \mathrm{m}^{2} \mathrm{~h}$, and the final resistances at the end of each filtration are plotted against $P_{V}$ in Fig. 4. Results suggest that the $P_{V}$ significantly affects the filtration performance. In general, the higher the applied electric power, the lower the fouling. A significant reduction of filtration resistance was 
achieved at a $P_{V}$ of $10.7 \mathrm{~W}$ or higher. This $P_{V}$ value beyond which no further reduction of fouling could be achieved is further referred to as the critical power.
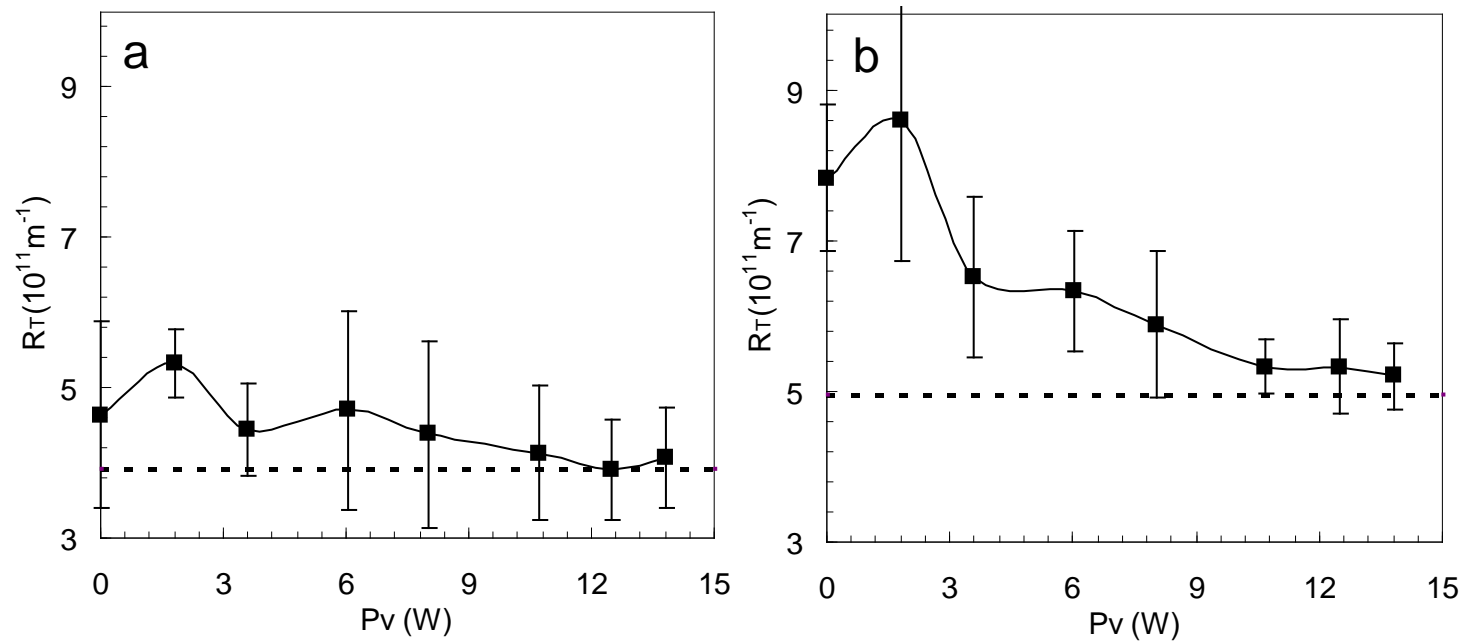

Fig. 4. Effect of $P_{V}$ on final filtration resistance using (a) $P V D F_{T}$ and (b) $P E_{K}$ membranes.

\subsubsection{Effect of vibration strategies}

\subsubsection{Continuous vs. intermittent vibration}

The effect of intermittent vibration on the filtration performance was tested at a $P_{V}$ of $8 \mathrm{~W}$ and a $\mathrm{J}$ of 22 $\mathrm{L} / \mathrm{m}^{2} \mathrm{~h}$. $P_{V}$ was chosen just below its critical value (Section 3.2.2) in order to detect even small changes of the fouling rates among the different filtration tests. The experiments were carried out in three different modes, al in the non-aerated zone: (1) filtration without vibration, (2) filtration with vibration and (3) filtration with intermittent vibration. The intermittent vibration consists of idle and vibration phases to form a cycle. The sum of the idle and vibration times in one cycle is defined as the total cycle time $\left(t_{C}\right)$, and the ratio of the vibration time to the $t_{C}$ is defined as the vibration ratio $(\alpha)$. In this particular filtration test, $t_{C}$ and $\alpha$ were set at 60 min and $50 \%$, respectively.

The results of different vibration strategies are presented in Fig. 5. As expected, filtration with continuous vibration gave the best performance, while the intermittent vibration resulted in somewhat higher but still acceptable final filtration resistance. A much higher filtration resistance was observed for the filtration without vibration. For instance, the $R_{F}$ values of filtrations in modes (1), (2) and (3) after 300 min of operation were found to be $84 \%, 13 \%$ and $43 \%$ of the $R_{T}$, respectively. A slow rise of filtration resistances for both vibration-assisted filtrations suggests that the vibration in MMV system can be operated in an intermittent mode, which offers an adequate fouling control and a reduced energy consumption. 


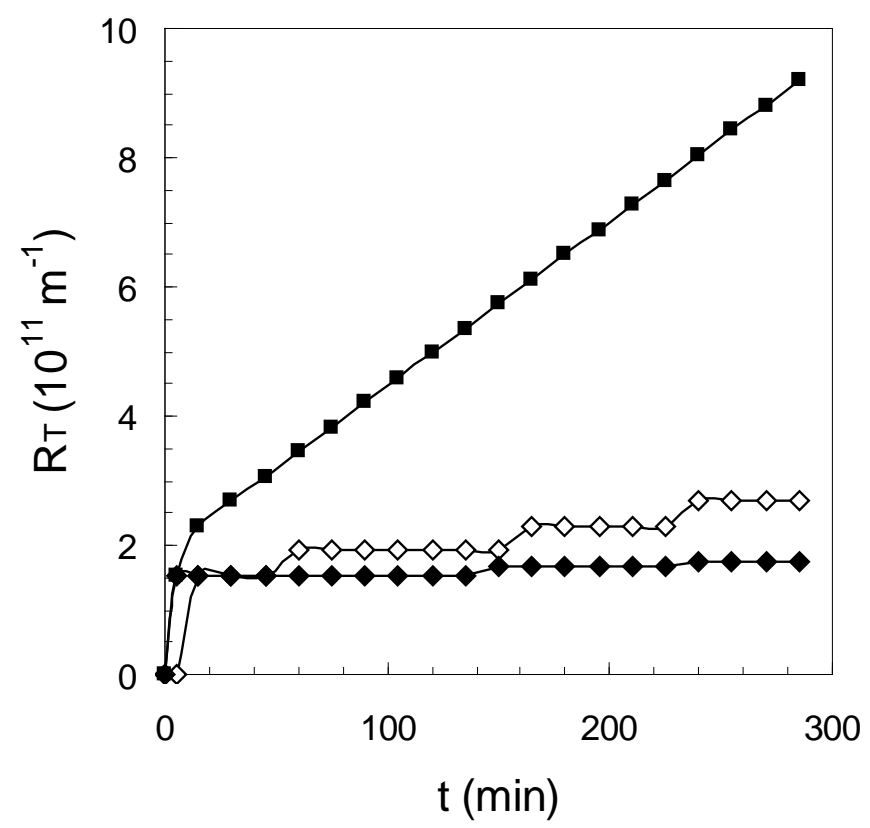

Fig. 5. Effect of different membrane vibration strategies: (घ) filtration with no vibration, $(\diamond)$ with (continuous) vibration and $(\diamond)$ with intermittent vibration ( $t_{c}: 60$ min and $\alpha: 50 \%$ ).

\subsubsection{Effect of intermittent cycle time}

The performance of the MMV system can be further optimised by varying both the $t_{C}$ and $\alpha$. In these particular experiments, $\alpha$ was fixed at $50 \%$ and $t_{C}$ was varied. The $P_{V}$ and $J$ were fixed at $8 \mathrm{~W}$ and 22 $\mathrm{L} / \mathrm{m}^{2} \mathrm{~h}$, respectively. Fig. 6 shows that $t_{C}$ strongly affects the filtration performance. For the longest $t_{C}(120$ $\mathrm{min})$, a sharp rise of fouling resistance occurred during the idle phases and the membrane permeability was only partially recovered during the vibration phases. On the other hand, filtrations at shorter $t_{C}$ resulted in lower filtration resistances. The $R_{F}$ values of filtration with $t_{C}$ of 120,24 and 4 min after 300 min of operation, were found to be $125 \%, 75 \%$ and $75 \%$ of the $R_{M}$, respectively. The lower fouling rates at shorter $t_{C}$ can be explained by the shorter idle phases, during which less aggressive fouling can be expected. This result confirms that the appropriate choice of $t_{C}$ for the MMV system is indispensable to ensure both an efficient and an economic operation. 


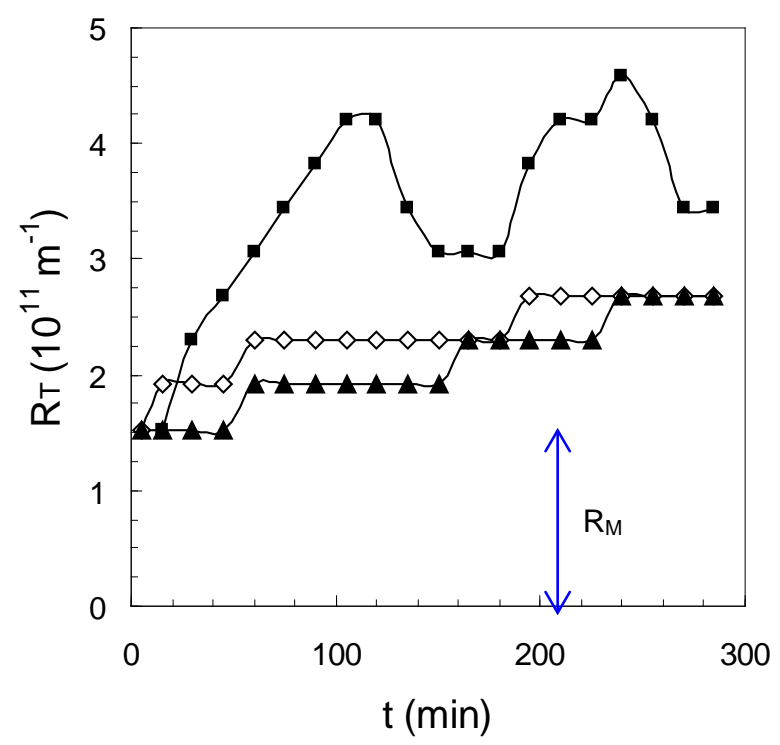

Fig. 6. Effect of intermittent cycle duration: filtration with vibration cycle of $(\boldsymbol{\square}) 120 \mathrm{~min},(\diamond) 24 \min$ and $(\boldsymbol{\Delta})$ $4 \min (\alpha: 50 \%)$.

\subsection{Operation flux and critical flux}

\subsubsection{Effect of operation flux on membrane fouling}

Flux is considered as one of the most important factors affecting membrane fouling in MBRs (Chang et al., 2002). Its appropriate selection is crucial to maintain the fouling rate at a satisfactory level during long-term operations. A series of filtrations was performed to investigate the effect of operational flux on filtration performance. The performance of both the vibrated filtration and the aerated filtration were compared, as shown in Fig. 7. The flux was varied between 14 and $30 \mathrm{~L} / \mathrm{m}^{2} \mathrm{~h}$, and the MMV system operated in an intermittent mode, with a $t_{C}$ of $4 \mathrm{~min}$, a $P_{V}$ of $8 \mathrm{~W}$ and an $\alpha$ of $50 \%$.

As expected, a faster rate of fouling was found at higher fluxes for both systems. The filtration resistance at the corresponding fluxes was always found to be significantly lower for the vibrating module. At $J=30$ $\mathrm{L} / \mathrm{m}^{2} \mathrm{~h}$, a sharp rise of filtration resistance was observed for both the aerated and the vibrated module. However, the MMV system experienced a much lower fouling at the flux ranges of $14-26 \mathrm{~L} / \mathrm{m}^{2} \mathrm{~h}$. These results suggest that the MMV system could ensure higher operational fluxes compared to conventional submerged MBR systems. 

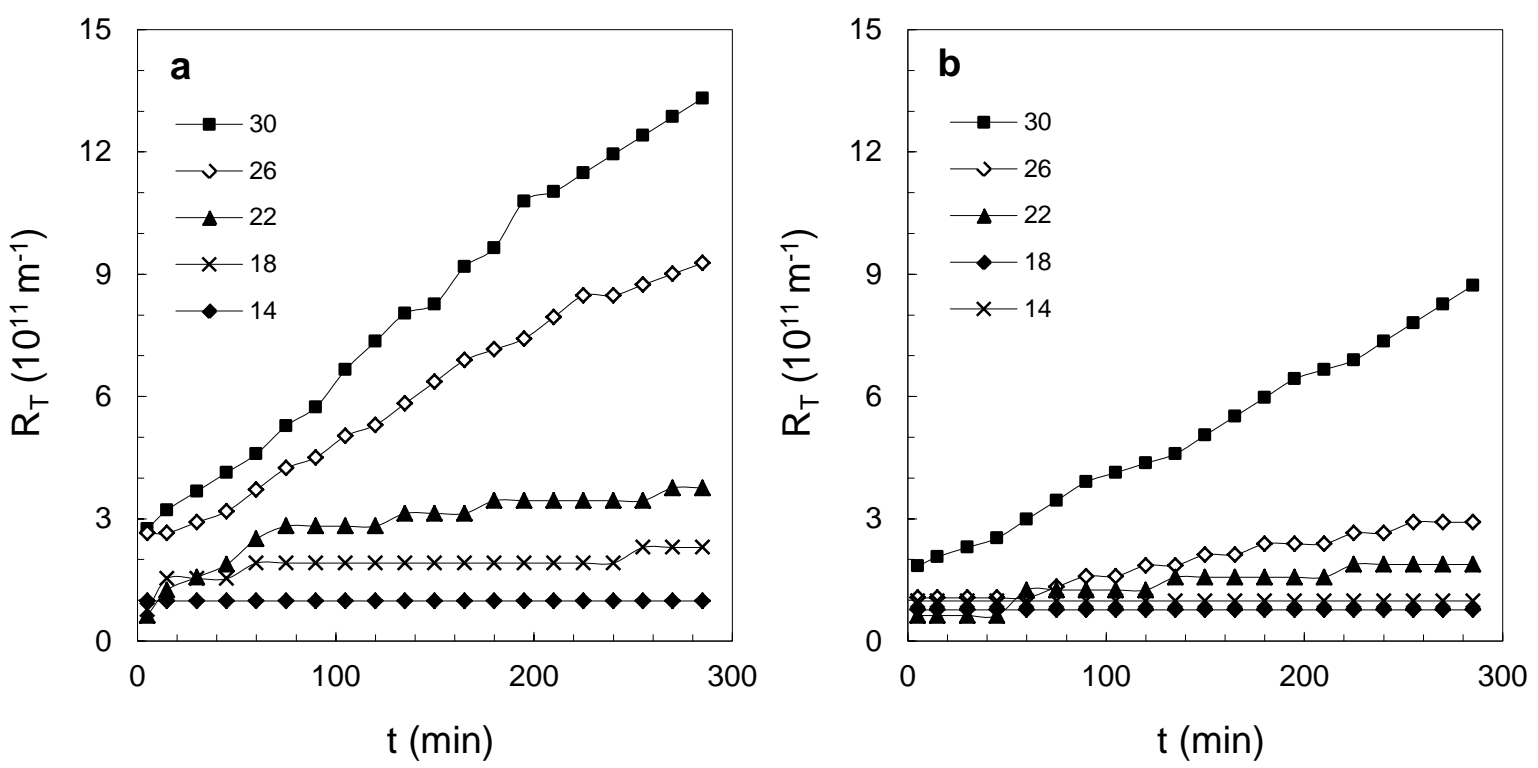

Fig. 7. Effect of operational flux on filtration resistance in (a) aerated system and (b) MMV system.

\subsubsection{Effect of vibration on critical flux}

Membrane fouling, in general, is managed by operating the system below its CF (Le-Clech et al., 2006). The CF is broadly defined as the maximum flux value, at which (theoretically) no particle deposition on the membrane surface occurs. This critical value depends on several factors such as the feed condition, membrane properties, hydrodynamics and operation conditions (Wu et al., 2008). The enhanced shear upon vibration can facilitate the increase of CF. Its correlation was evaluated by measuring CF values at different $P_{V}$ (Fig. 8). The experiment was carried out at $\alpha=100 \%$ and at a constant vibration frequency of $50 \mathrm{~Hz}$. The $P_{V}$ was adjusted by varying the vibration amplitude.

Fig. 8 indicates that the higher the $P_{V}$, the higher the CF, in accordance with the literature (Genkin et al., 2006; Beier et al, 2006; Altaee et al., 2010). For example, a CF value of $46 \mathrm{~L} / \mathrm{m}^{2} \mathrm{~h}$ was obtained at a $P_{V}$ of 15.4 W, which is about 3 times higher than the CF measured for the similar feed and membrane in a conventional aerated lab-scale MBR (Bilad et al., 2011 ${ }^{\mathrm{a}}$ ). The $P_{V}$ and CF were found to be proportional in the range of the studied $P_{V}$. The intercept with the y-axis in Fig. 8 gives the CF for the non-vibrating operation. Since the MMV system is operated at a fixed frequency, $P_{V}$ is proportional here to the applied vibration amplitude, and that is in line with earlier findings for the VHFM system (Beier et al, 2006). 


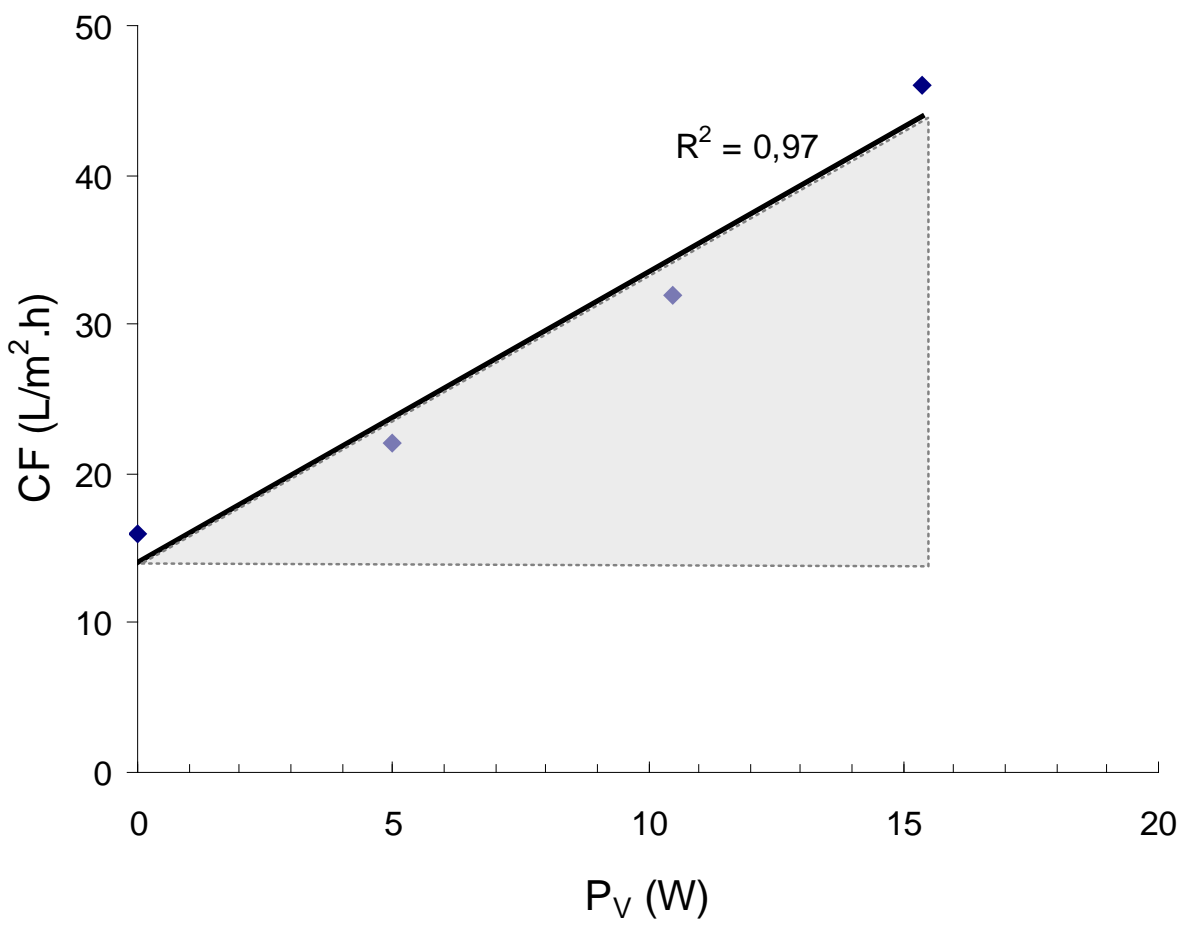

Fig. 8. CF determined at different $P_{V}$ s. The shaded area represents optional conditions at which filtration is enhanced due to the additional shear caused by the membrane vibration.

\subsection{Long-term filtration, multiple membranes operation and energy consumption}

The applicability of the MMV system to control membrane fouling in short-term filtration duration has been proven in the previous sections. However, a filtration test over an extended time frame is indispensable to provide more convincing results. In the following experiments, the activated sludge filtration was studied from two different aspects: (1) examining the long-term filtration resistance profile and (2) investigating the effect of multiple membranes in the MMV system to allow evaluation of the energy consumption.

\subsubsection{Long-term filtration}

Since the membrane used is different from the one used in Sections 3.2.3 and 3.3, preliminary experiments were performed to select the optimum values for $t_{C}, \alpha$ and $P_{V}$. In order to better represent the full-scale operation, the filtration was now performed with a relaxation time included in the intermittent filtration. The choice of filtration cycle duration and ratio was also based on a preliminary experiment in which both of these parameters were varied. The results of the aforementioned preliminary experiments are provided as supplementary material.

For the long-term filtration, the filtration was operated in a 5 min cycle that consisted of 4.5 min of filtration and $0.5 \mathrm{~min}$ of relaxation. The experiment was performed in two sequential runs. Initially, $5 \mathrm{PE}_{\mathrm{K}}$ membranes were run in parallel. Two membrane were operated in the aerated zone, and 3 membranes were operated with vibration. The distance between the membranes in the MMV system was about $5 \mathrm{~mm}$. 
The operational parameters $J, P_{V}, t_{C}$ and $\alpha$ for the MMV were set at $16 \mathrm{~L} / \mathrm{m}^{2} \mathrm{~h}, 6.4 \mathrm{~W}, 5 \mathrm{~min}$ and $50 \%$, respectively. The applied flux was selected as the flux generally applied for the particular membrane in fullscale applications, and the $P_{V}$ was obtained as the result of a preliminary test. $P_{V}$ was set to be low enough to reduce energy consumption, but high enough to provide an acceptable fouling control.

Fig. 9 shows the profile of the filtration resistances during the long-term filtration. After seven days of operation, fouling was found to be more severe for all modules in the vibrated system compared to the ones in the aerated system. This is an obvious contradiction with all the previous results, but can be explained by the arrangement of the membranes. The strongest resistance increase was observed in the case of the vibrated membrane in the second position (i.e. situated between the two others), suggesting an inappropriate distance between the membranes. Apparently, the membranes in the MMV system, were situated so near to each other that the liquid between the membranes moved in-phase an almost became stagnant, moving together with the membrane. To confirm this hypothesis, the filtration was stopped, the second (middle) vibrated membrane was omitted from the reactor, and the filtration was continued. The remaining membranes were chemically cleaned prior to the filtration re-start.

Fig. 9 clearly shows that the two vibrating membranes (now with a distance of $10 \mathrm{~mm}$ in between) performed better in terms of fouling than the aerated ones throughout the 15 extra days of operation, even though membrane 3 showed a jump on days 13-16 which can not be explained. These results not only confirm the efficacy of the MMV system in a long-term filtration process, but also suggest the importance of adequate design and arrangement of the membranes in one module.

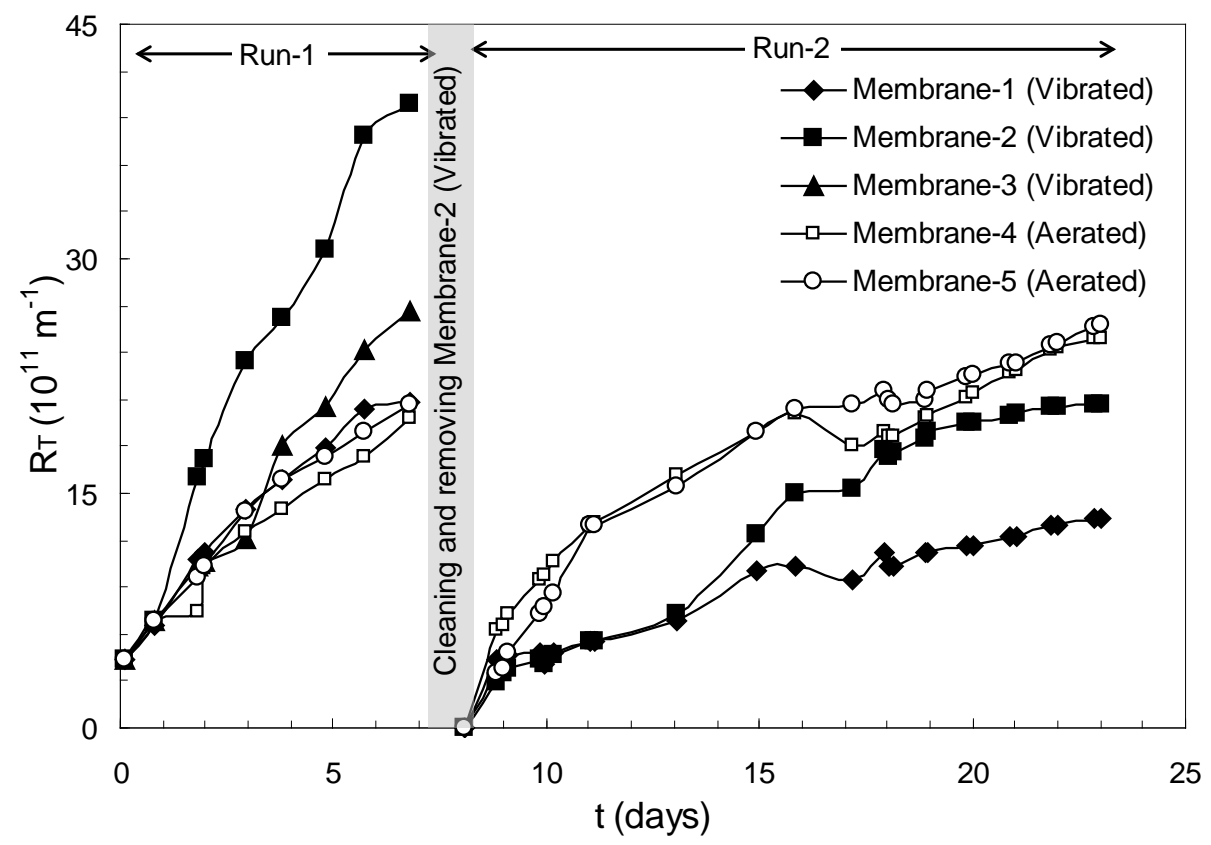

Fig. 9. The profile of filtration resistance during the long-term filtration. Membranes 1-3 were operated in the MMV system, and membranes 4-5 operated in a normal submerged aerated MBR.

\subsubsection{Multiple membrane operation and energy consumption}

The reduction of energy consumption associated with fouling control is currently one of the main objectives in MBR research. The energy consumption of submerged MBRs is several times higher than that of 
conventional activated sludge processes (Cornel et al., 2003), and it mainly comes from the energy associated with the coarse bubble aeration for fouling control (Gander et al., 2000). The use of MMV system might offer a promising alternative as a new approach to control fouling in the MBRs. In most shearenhanced filtration systems, the energy consumption $\left(E D, k W h / \mathrm{m}^{3}\right)$ is dominated by the energy that is consumed by the vibration engine. Therefore, the energy consumption associated with the MMV system was monitored during this particular test. However, since the ED is calculated based on the volume of permeate, the scale of the plant becomes very significant, mostly favoring large scale applications. To evaluate the ED of the MMV system, the filtration with multiple membranes was conducted. The MMV system was loaded with up to 6 membranes, to check if there were any changes in filtration performance when the number of membranes in the module increased.

Six filtration runs with activated sludge were performed with the MMV system, with each time a different numbers of membranes attached to the module. One additional filtration with six membranes in one module was also performed without vibration for comparison. The filtration parameters were set at $\mathrm{J}$ of $16 \mathrm{~L} / \mathrm{m}^{2} \mathrm{~h}$ and $P_{V}$ of $6.4 \mathrm{~W}$, similar to the values used in the long-term test.

The profile of the resistance of filtration with different numbers of membranes on the MMV system is shown in Fig. 10. The filtration resistances are given as the average values and the deviations are represented by the shaded area. The results suggest that the lab-scale MMV system could sustain with at least six membranes (each has $0.016 \mathrm{~m}^{2}$ effective area). The addition of up to six membranes did not significantly affect the filtration performance. This result is in line with the new generation of VSEP system, where increasing the membrane area does not significantly affect significantly the ED (Jaffrin, 2008). The addition of more membranes to the MMV system was not feasible in the current set-up, due to the limited space available inside the lab-scale reactor tank.

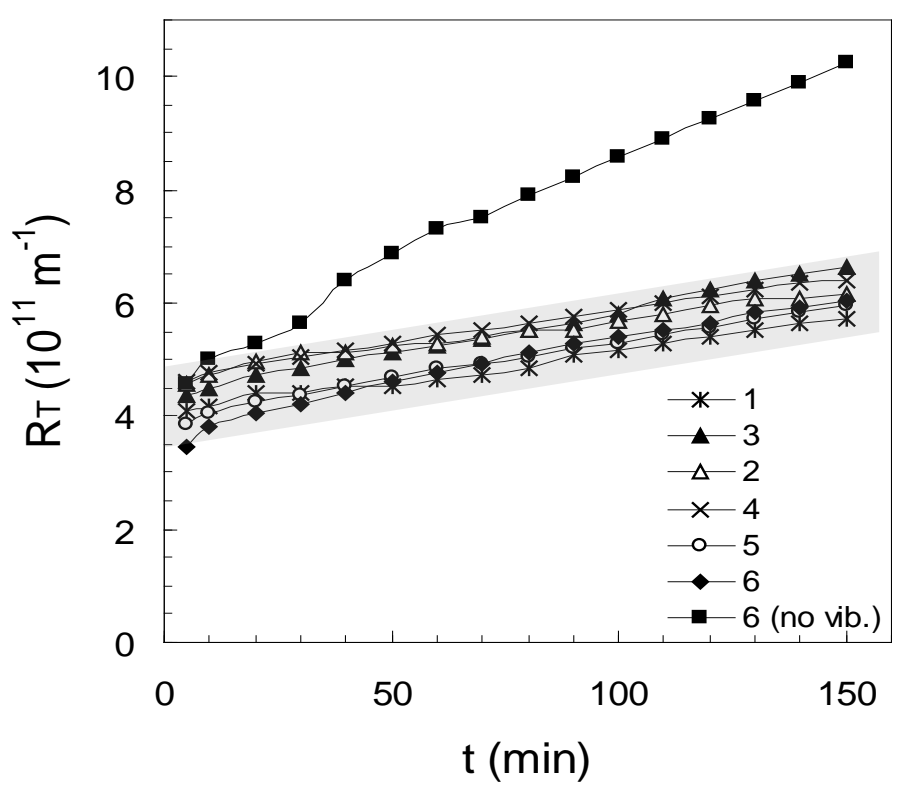

Fig. 10. The profile of the filtration resistance for the filtration with different number of membranes mounted on the MMV system.

The available information on energy consumption of full- or pilot-scale MBRs in scientific literature is scarce. Table 2 contains some related data of selected publications from the last 5 years and furthermore includes ED data from the lab-scale MMV system. The ED associated with the MMV system was calculated 
by using a $J, P_{V}$ and $\alpha$ of $16 \mathrm{~L} / \mathrm{m}^{2} \mathrm{~h}, 6.4 \mathrm{~W}$ and $50 \%$ respectively, similar to the ones used in the long-term test.

Table 2 also confirms that the ED associated with coarse bubble aeration is strongly affected by plant scale. The ED of the pilot-scale MBR (Fenu et al., 2010) is almost ten times the one of the full-scale ones. This should be considered when analyzing the lab-scale MMV system data. Calculating the ED using six membranes $\left(2.03 \mathrm{kWh} / \mathrm{m}^{3}\right)$ gives a 6 times smaller value than with one membrane $\left(12.12 \mathrm{kWh} / \mathrm{m}^{3}\right)$. Nevertheless, this value is much lower than the ED of a pilot-scale MBR that operates with a \pm 160 time larger membrane area, suggesting a rather economic design of the system, despite being far from optimized yet. It is worth noting that the ED of the lab-scale MMV system is about 3.5 times higher than the ED of the best performing full-scale MBR listed in Table 2. However, direct comparison of these data is not entirely reliable, since the ED a lab-scale set-up is not of economical scale and the feed and sludge characteristics of an MBR have a serious influence on the filtration performance. From these comparisons, it can thus be expected that an optimised MMV system (Frequency, amplitude, vibration cycle,....) may lead to a significant cost reduction for fouling control in MBRs. With even membrane moving in one direction and odd membrane in the other, more compact, but still efficient modules could possibly be realized.

Table 2. Energy demand of lab-scale MBR and comparison with literature data.

\begin{tabular}{lcccc}
\hline Reactor (membrane) & ED $\left(\mathrm{kWh} \mathrm{m}^{-3}\right)$ & $\mathrm{J}\left(\mathrm{L} \mathrm{m}^{-2} \mathrm{~h}^{-1}\right)$ & $\mathrm{A}\left(\mathrm{m}^{2}\right)$ & reference \\
\hline lab-scale MBR (KUBOTA flat sheet) & $12.12^{\mathrm{a}}$ & 16 & 0.016 & present study \\
& $2.03^{\mathrm{b}}$ & & 0.096 & \\
pilot-scale MBR (KUBOTA flat sheet) & 6.06 & 19 & 16 & (Fenu et al., 2010) \\
& 4.88 & 25 & & \\
full-scale MBR (Zenon hollow fibre) & 0.64 & 23 & 10,160 & (Fatone et al., 2007) \\
full-scale MBR (Zenon hollow fibre) & $<0.60$ & 26 & 12,130 & (Verrecht et al., 2010) \\
full-scale MBR (hollow fibre) & & 20 & 63,366 & (Gil et al., 2010)
\end{tabular}

${ }^{\mathrm{a}}$ Calculated from $P_{V}$ with one vibrating membrane in the reactor. ${ }^{\mathrm{b}}$ Calculated from $P_{V}$ with six vibrating modules in the reactor. ${ }^{\mathrm{C}}$ Theoretical set-up for cost sensitivity analysis. 


\section{Conclusions}

Innovative magnetically induced membrane vibration proved very promising in a lab-scale MBR treating synthetic wastewater treatment. Results of both the filtration and the CF measurements showed clear advantages of this system over conventional MBR processes in terms of realisable flux and fouling control. Significant improvement of CF was obtained due to the enhanced shear at the liquid-membrane interface. The filtration was found sensitive to several operation factors such as the vibration parameters (e.g., vibration power and cycles) and the applied flux. The long-term experiments confirmed the efficacy of the MMV system, but also suggested the importance of an appropriate membrane arrangement in the MBR in the module. The energy demand of vibration, resulting in the highest of all the MBR costs, was found practically constant when the number of modules mounted in the MMV system was increased from one up to six, while increasing treated water volumes 6-fold.. The MMV-aided filtration, after process optimisation, is expected to lead to significant cost less membrane area to be installed when taking advantage of the higher CF) and energy (especially when expending the number of membranes per module) reduction in (up-scaled) MBRs. This novel membrane fouling limitation method seems very promising in MBRs, but also for the currently progressing anaerobic MBRs where coarse air bubbling is not an option, and possibly also other fouling sensitive ultrafiltration (UF) and nanofiltration (NF) operations, like algae harvesting.

\section{Abbreviations and symbols}

\begin{tabular}{|c|c|}
\hline$A$ & Membrane surface area $\left(\mathrm{m}^{2}\right)$ \\
\hline CF & (normalised) Critical flux $\left(\mathrm{L} / \mathrm{m}^{2} \mathrm{~h}\right)$ \\
\hline ED & Energy demand $\left(\mathrm{kWh} / \mathrm{m}^{3}\right)$ \\
\hline$J$ & Permeate flux $\left(\mathrm{L} / \mathrm{m}^{2} \mathrm{~h}\right)$ \\
\hline$J_{V}$ & Permeate flow velocity (m/s) \\
\hline$L$ & Membrane permeability $\left(\mathrm{L} / \mathrm{m}^{2} \mathrm{~h} \mathrm{~Pa}\right)$ \\
\hline MBR & Membrane bioreactor \\
\hline MLSS & Mixed liquor suspended solid (g/L) \\
\hline MMV & Magnetically induced membrane vibration \\
\hline NF & Nanofiltration \\
\hline$P_{V}$ & Vibration power $(\mathrm{W})$ \\
\hline$P E_{K}$ & Polyethylene (Kubota) \\
\hline $\mathrm{PVDF}_{\mathrm{T}}$ & Polyvinylidene fluoride (Toray) \\
\hline$R_{F}$ & Fouling resistance $\left(\mathrm{m}^{-1}\right)$ \\
\hline$R_{M}$ & Intrinsic embrane resistance $\left(\mathrm{m}^{-1}\right)$ \\
\hline$R_{T}$ & Filtration resistance $\left(\mathrm{m}^{-1}\right)$ \\
\hline$t$ & Filtration time \\
\hline$t_{C}$ & Vibration cycle time $(\mathrm{min})$ \\
\hline TMP & Trans-membrane pressure $(\mathrm{Pa})$ \\
\hline SVI & Sludge volume index (mL/g) \\
\hline UF & Ultrafiltration \\
\hline$\Delta V$ & Permeate volume (L) \\
\hline
\end{tabular}




$\begin{array}{ll}\alpha & \text { Intermittent vibration fraction (\%) } \\ \eta & \text { Dynamic viscosity of permeate (Pa s) }\end{array}$

\section{Acknowledgements}

The authors gratefully acknowledge the financial support provided by K.U. Leuven (CECAT excellence, GOA and IDO financings), by the Flemish Government (Methusalem funding) and by the Federal Government (IAP grant). Special thanks to: Waterleau for providing the sludge seed and giving technical support at start-up of the lab-scale MBR; Wim Ruttens (Intellitech) for his very useful help in the system development; and Toray Membrane Europe for providing the A4 size membrane element samples. 


\section{REFERENCES}

Altaee A., Al-Rawajfeh A.E., Baek Y.J., 2010. Application of vibratory system to improve the critical flux in submerged hollow fiber MF process. Separation Science and Technology 45 (1), 28-34.

American Public Health Association/American Water Works Association (APHA)Mater Environment Federation, 1992. Standard methods for the examination of water and wastewater, 18th ed. Washington DC, USA.

Beier S.P., Guerra M., Garde A., Jonsson G., 2006. Dynamic microfiltration with a vibrating hollow fiber membrane module: Filtration of yeast suspensions. Journal of Membrane Science 281 (1-2), 281287.

Beier S.P., Jonsson G., 2007. Separation of enzymes and yeast cells with a vibrating hollow fiber membrane module. Separation and Purification Technology 53 (1), 111-118.

Beier, S.P. 2008. Dynamic microfiltration - critical flux and macromollecular transmission, Ph.D. dissertation, Technical University of Denmark.

Beier S.P., Jonsson G., 2009. A vibrating membrane bioreactor (VMBR): Macromolecular transmissioninfluence of extracellular polymeric substances, Chemical Engineering Science 64 (7), 1436-1444.

Bilad M.R., Declerck P., Piasecka A., Vanysacker L., Yan X., Vankelecom I.F.J., 2011 ${ }^{\text {a }}$. Development and validation of a high-throughput membrane bioreactor (HT-MBR). Journal of Membrane Science: doi:10.1016/j.memsci.2011.05.052.

Bilad M.R., Declerck P., Piasecka A., Vanysacker L., Yan X., Vankelecom I.F.J., 2011 ${ }^{\mathrm{b}}$. Treatment of molasses wastewater in a membrane bioreactor: Influence of membrane pore size. Separation and Purification Technology 78 (2), 105-112.

Bilad, M.R., Westbroek, P., Vankelecom, I.F.J. 2011 ${ }^{\mathrm{c}}$. Assessment and optimization of electrospun nanofiber-membranes in a membrane bioreactor (MBR), J. Membrane Sci. 380, 181-191.

Chang I-S., Le-Clech P., Jefferson B., Judd S.J., 2002. Membrane fouling in membrane bioreactors for wastewater treatment. Journal of Environmental Engineering 128 (11),1018-1029.

Cornel P., Wagner M., Krause S., 2003. Investigation of oxygen transfer rates in full scale membrane bioreactors. Water Science and Technology 47 (11), 313-319.

Cui Z.F., Chang S., Fane A.G., 2003. The use of gas bubbling to enhance membrane processes, Journal of Membrane Science 221 (2003) 1-35.

Drews A., 2010. Membrane fouling in membrane bioreactors - Characterisation, contradictions, cause and cures. Journal of Membrane Science 363 (1-2) 1-28.

Drews A., Evenblij H., Rosenberger S., 2005. Potential and drawbacks of microbiology-membrane interaction in membrane bioreactors. Environmental Progress. 24 (4), 426-433.

Fatone F., Battistoni P., Pavan P., Cecchi F., 2007. Operation and maintenance of full-scale municipal membrane biological reactors: A detailed overview on a case study. Industrial \& Engineering Chemistry Research 46 (21), 6688-6695.

Fenu A., Roels J., T. Wambecq T., De Gussem K., Thoeye C., De Gueldre G., Van De Steene B., 2010. Energy audit of a full scale MBR system. Desalination 262 (1-3), 121-128.

Gander M., Jefferson B., Judd S., 2000. Aerobic MBRs for domestic wastewater treatment: a review with cost considerations. Separation and Purification Technology 18, 119-130.

Genkin G., Waite T.D., Fane A.G., Chang S., 2006. The effect of vibration and coagulant addition on the filtration performance of submerged hollow fibre membranes. Journal of Membrane Science 281 (1-2), 726-734.

Gil J.A., Túa L., Rueda A., Montaño B., Rodríguez M., Prats D., 2010. Monitoring and analysis of the energy cost of an MBR. Desalination 250 (3), 997-1001.

Jaffrin M.Y., 2008. Dynamic shear-enhanced membrane filtration: A review of rotating disks, rotating membranes and vibrating systems. Journal of Membrane Science 324 (1-2), 7-25.

Kola, A., Ye, Y., Stuetz, R., Le-Clech, P., Chen, V. Transverse vibration as a fouling limitation strategy in membrane bioreactors. Oral presentation presented at ICOM 2011, Amsterdam, The Netherlands, July 23-29 (2011).

Le-Clech P., Jefferson B., Chang I.S., Judd S.J., 2003. Critical flux determination by the flux-step method in a submerged membrane bioreactor. Journal of Membrane Science 227 (1-2), 81-93.

Le-Clech, P., Chen, V., Fane T.A.G., 2006. Fouling in membrane bioreactors used in wastewater treatment. Journal of Membrane Science 284 (1-2), 17-53.

Low S.C., Cheong K.T., Lim H.L., 2009. A vibration membrane bioreactor. Desalination and Water Treatment 5, 42-47.

Meng F., Chae S.-R,. Drews A., Kraume M., Shin H.-S., Yang F., 2009. Recent advances in membrane bioreactors (MBRs): Membrane fouling and membrane material. Water Research 43 (6), 1489-1512.

Vankelecom I.F.J., Smet K.D., Gevers L., Jacobs P., Preparation of NF-membranes, in: Schäfer A., Fane A., Waite T. (Eds.), Nanofiltration - Principles and applications, Elsevier, Amsterdam, The Netherlands, 2004, 33-65.

Verrecht B., Maere T., Nopens I., Brepols C., Judd S., 2010. The cost of a large-scale hollow fibre MBR. Water Research 44 (18), 5274-5283. 
Rosenberger, S., Kraume, M. 2003. Filterability of activated sludge in membrane bioreactors. Desalination 151, 195-200.

Wu Z., Wang Z., Huang S., Mai S., Yang C., Wang X., Zhou Z., 2008. Effects of various factors on critical flux in submerged membrane bioreactors for municipal wastewater treatment, Separation and Purification Technology 62 (1), 56-63.

Yan, X., Gerards, R., Vriens, L., Vankelecom, I.F.J. 2010. Hollow fiber membrane fouling and cleaning in a membrane bioreactor for molasses wastewater treatment, Desalination and Water Treatment 18, 192-197. 


\section{SUPPLEMENTARY MATERIALS}

\section{A. The effect of vibration frequency}

Table A1. The parameters applied when studying the effect of vibration frequency tests.

\begin{tabular}{lllll}
\hline Run & $\begin{array}{l}\text { Frequency } \\
(\mathrm{Hz})\end{array}$ & Current (Ampere) & Potential (volt) & $P_{V}(\mathrm{~W})$ \\
\hline A & 40 & 0,91 & 7,58 & 6,90 \\
B & 45 & 0,83 & 7,53 & 6,25 \\
C & 50 & 0,82 & 8,17 & 6,70 \\
D & 55 & 0,75 & 8,25 & 6,19 \\
E & 60 & 0,74 & 8,87 & 6,56 \\
\hline
\end{tabular}

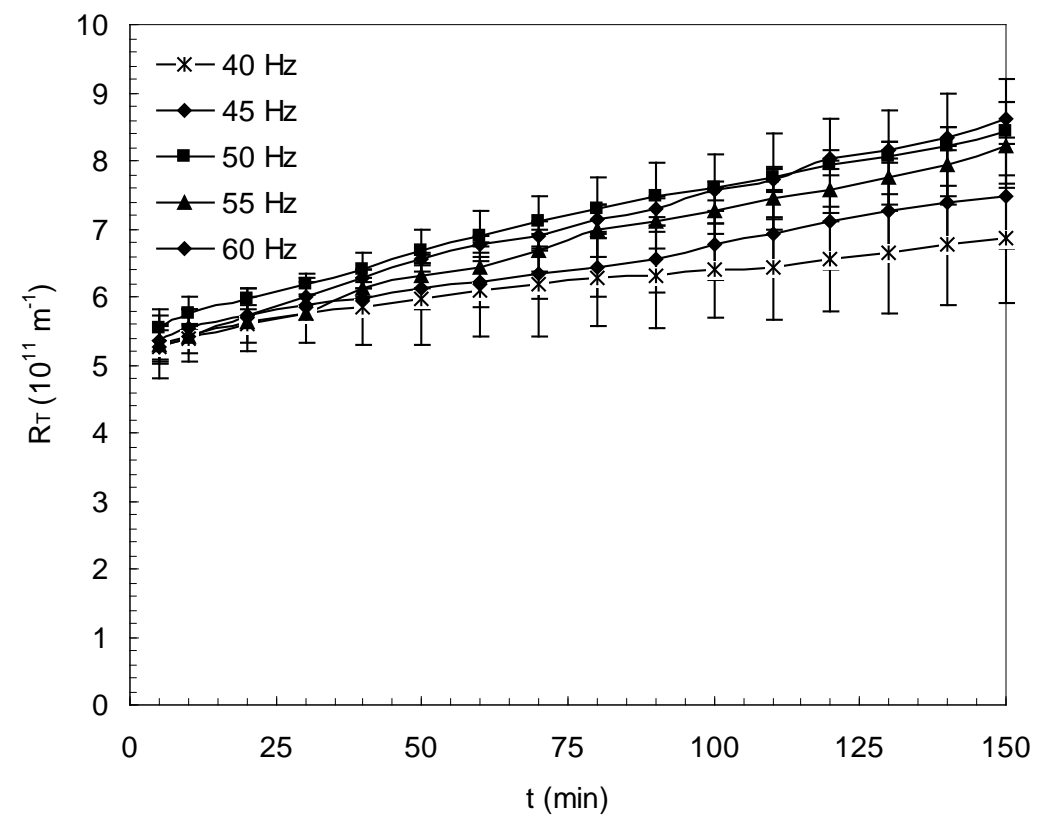

Fig. A1.

Effect of vibration frequency on the performance of the filtration. The $P_{V}$ was set at the same value as listed in Table B1. The filtrations $(n=3)$ were performed at a J of $25 \mathrm{~L} / \mathrm{m}^{2} \mathrm{~h}$ and $\alpha=100 \%$. 


\section{B. The effect of filtration cycle}

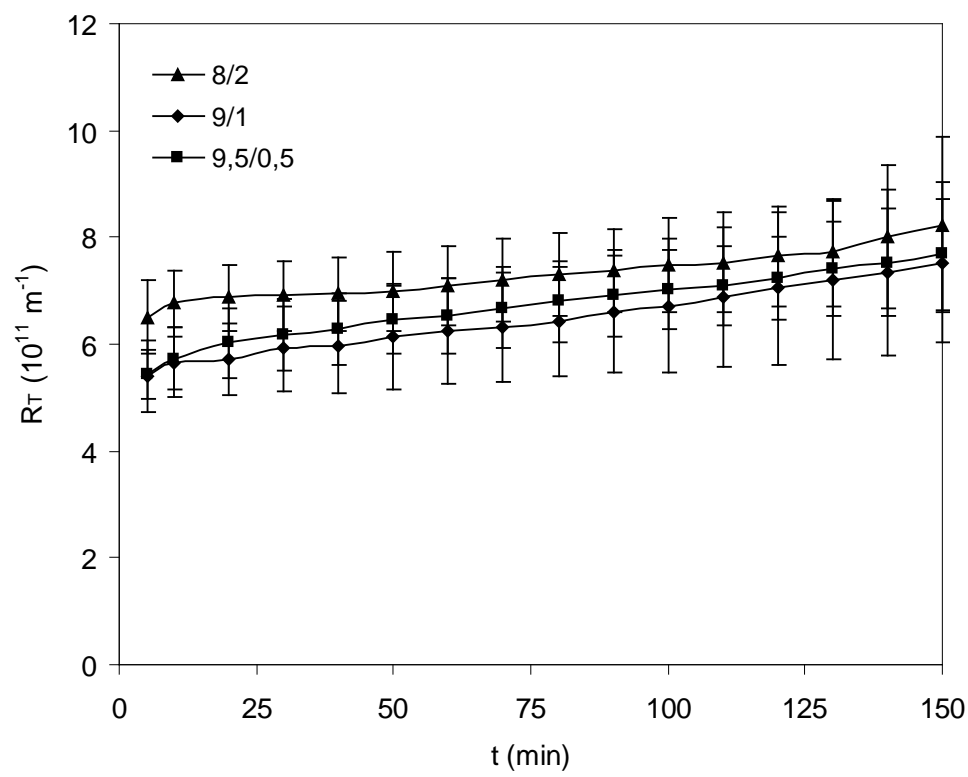

Fig. B1.

The effect of the filtration cycle duration on the filtration performance. The relaxation time was fixed to be $10 \%$ of the cycle duration. The filtrations $(n=3)$ were performed at a J of $25 \mathrm{~L} / \mathrm{m}^{2} \mathrm{~h}$ and $\alpha=100 \%$.

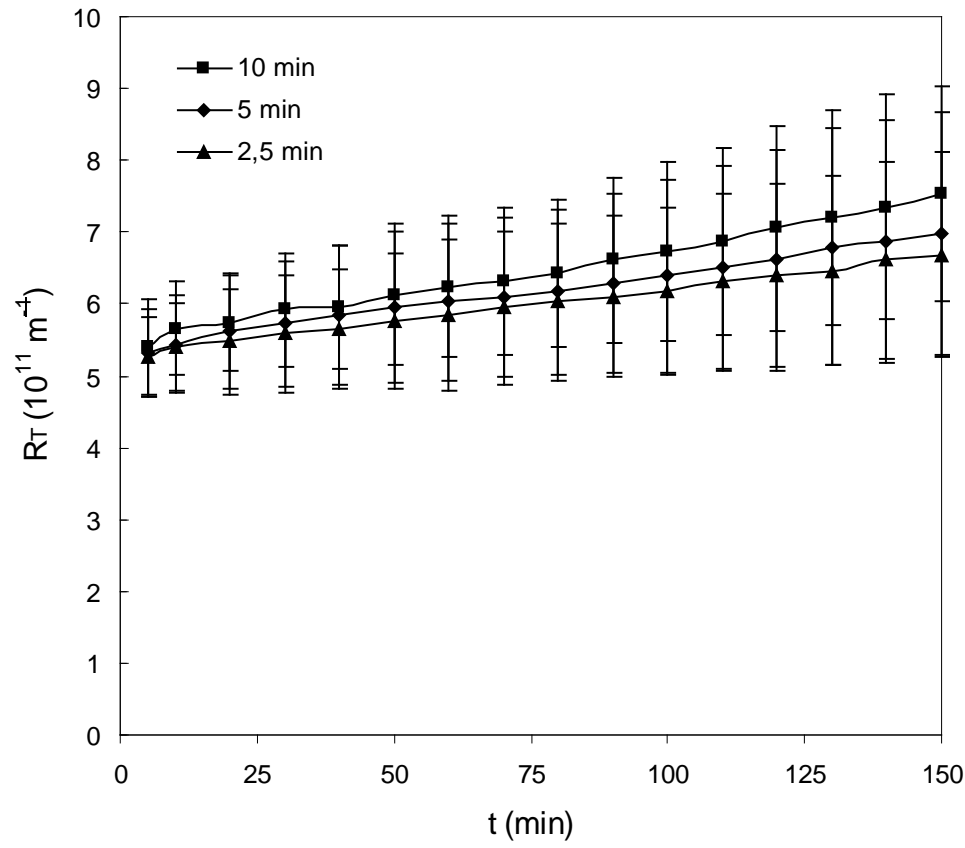

Fig. B2.

The effect of the ratio of filtration/ to relaxation in the filtration cycle on the filtration performance. The legend in the Fig. B2, represents the ratio of filtration to relaxation. The filtrations $(n=3)$ were performed at a $\mathrm{J}$ of $25 \mathrm{~L} / \mathrm{m}^{2} \mathrm{~h}$ and $\alpha=100 \%$. 
Dienst Onderzoekscoördinatie Huis Bethlehem Schapenstraat 34

B-3000 Leuven

Tel.: +3216324065

Fax: +3216324198

onderzoek@kuleuven.be

www.kuleuven.be 